\title{
Ludwig's angina after severe thrombocytopenic purpura associated with dengue fever
}

\section{Maria Antonia Campos ${ }^{[1]}$, Mário Lúcio Cerqueira Prota Junior ${ }^{[1]}$, Carlos Augusto Gomes ${ }^{[1]}$, Karina Peisino do Amaral ${ }^{[2]}$ and Diogo Campos Almeida ${ }^{[2]}$}

[1]. Departamento de Clínica Médica, Hospital Maternidade Terezinha de Jesus, Faculdade de Medicina e Ciências da Saúde de Juiz de Fora, Juiz de Fora, MG. [2]. Departamento de Cirurgia, Hospital Maternidade Terezinha de Jesus, Faculdade de Medicina e Ciências da Saúde de Juiz de Fora, Juiz de Fora, MG.

\begin{abstract}
Here, we report a case of Ludwig's angina, which required surgery because of toothache. The patient had dengue and severe thrombocytopenia as confirmed by clinical and laboratory diagnoses. However, dengue is not included among the predisposing factors for Ludwig's angina.
\end{abstract}

Keywords: Ludwig’s angina. Dengue. Thrombocytopenia.

\section{INTRODUCTION}

Ludwig's angina, described by the German doctor Karl Friedrich Wilhelm Von Ludwig in 1836, is a lethal and progressive gangrenous cellulitis with a mortality rate that exceeds $50 \%$. It primarily occurs in the region of the submandibular glands, leading to soft tissue swelling in the neck and floor of the mouth. However, with improvements in oral health and dentistry conditions, early surgical interventions, and broad-spectrum antimicrobial therapy, mortality due to Ludwig's angina has significantly reduced ${ }^{1}$.

The disease mainly affects young men (aged 20-40 years), and dental manipulation is the main cause described thus far. Predisposing factors include intravenous drug use, diabetes mellitus, systemic lupus erythematosus, alcoholism, malnutrition, a compromised immune system, organ transplantation, and trauma ${ }^{2}$.

Dengue is considered one of the primary global public health issues as well as specifically in Brazil. Approximately 550,000 patients are hospitalized, and 20,000 die due to complications ${ }^{3}$. Classic dengue (CD) can lead to leukopenia and hemorrhagic conditions, which are usually mild and include petechiae, purpura, epistaxis, gingivorrhagia, metrorrhagia, and moderate gastrointestinal bleeding ${ }^{4}$.

This case report aimed at discussing the possible pathophysiologic mechanisms involved in Ludwig's angina and the importance of early recognition and intervention.

\footnotetext{
Address to: Dr- Maria Antonia Campos. R. Fortaleza 15/106, 36039-090 Juiz de Fora, MG, Brasil.

Phone: 5532 3233-0186

e-mail: profmariaantoniacampos@yahoo.com.br

Received 6 October 2013

Accepted 31 January 2014
}

\section{CASE REPORT}

A 29-year-old man was hospitalized after presenting with diffuse petechial hemorrhage (ecchymosis and gingival bleeding) with no other associated symptoms. The hemorrhage started 10 days after an episode of CD fever, confirmed by positive serological method anti-dengue ELISA. He developed severe thrombocytopenia $\left(<1,000 / \mathrm{mm}^{3}\right)$ and had to receive a concentrated platelet transfusion (Table 1). Corticosteroid therapy was initiated because of the persistence of these clinical symptoms. The patient remained asymptomatic after the therapy, and he was discharged upon medication.

A week later, the patient developed a severe toothache, as assessed by topography of the left lower molars. Surgery was recommended and performed with no complications. However, the pain intensified, and the next day the patient was admitted to the emergency care unit because of swelling in the left submandibular region. Because dental infection was suspected, antibiotic therapy was prescribed. However, the symptoms worsened quickly, and the patient had to be transferred to the intensive care unit (ICU) because of respiratory failure.

In the ICU, the patient presented with severe ventilatory insufficiency, cervical edema, and tongue protrusion (Figure 1A) in addition to glottis edema, laryngeal stridor, and trismus. Because it was clinically impossible to perform orotracheal intubation, the patient underwent an emergency tracheotomy. Treatments included hemodynamic and ventilatory support, intravenous antibiotic therapy using piperacillin/tazobactam, intravenous hydrocortisone, and platelet transfusions. Further, a cervical computed tomography (CT) scan was performed (Figure 1B).

Eight days after the second hospitalization, the left submandibular swelling developed into an abscess (size, $6.0 \times 1.5 \mathrm{~cm}$ ), which was diagnosed by ultrasound. The purulent secretion was drained, and the patient was discharged, after which he resumed work. 
TABLE 1 - The evolution of laboratory findings of a patient with dengue fever and Ludwig's angina.

\begin{tabular}{|c|c|c|c|c|c|c|}
\hline Variable & $\begin{array}{l}\text { Reference } \\
\text { range, adults }\end{array}$ & $\begin{array}{l}10 \text { days after } \\
\text { presentation } \\
\text { of dengue, on } \\
\text { admission }\end{array}$ & $\begin{array}{c}4^{\text {th }} \text { hospital } \\
\text { day - } \\
\text { discharged }\end{array}$ & $\begin{array}{l}1 \text { week after } \\
\text { hospital discharge; } \\
\text { readmission - } \\
\text { diagnosis of } \\
\text { Ludwig's Angina }\end{array}$ & $\begin{array}{c}4^{\text {th }} \text { hospital } \\
\text { day - intensive } \\
\text { care unit }\end{array}$ & $\begin{array}{c}13 \text { days after } \\
\text { presentation of } \\
\text { Ludwig's Angina }\end{array}$ \\
\hline Hemoglobin (g/dL) & $11.5-17.0$ & 13.5 & 13.7 & 11.8 & 9.1 & 13.3 \\
\hline Hematocrit (\%) & $37.0-54.0$ & 13.4 & 40.5 & 35.2 & 27.5 & 40.3 \\
\hline \multicolumn{7}{|l|}{ Differential count $(\%)$} \\
\hline Neutrophils & $40-70$ & 37.0 & 68.0 & 81.0 & 76.0 & 73.6 \\
\hline Band forms & $0-4$ & & & 16.0 & 5.0 & \\
\hline Lymphocytes & $20-50$ & $56.0 *$ & 25.0 & 2.0 & 15.0 & 18.9 \\
\hline Platelet count (per $\mathrm{mm}^{3}$ ) & $150,000-400,000$ & 1,000 & 12,000 & 1,000 & 11,000 & 63,000 \\
\hline
\end{tabular}

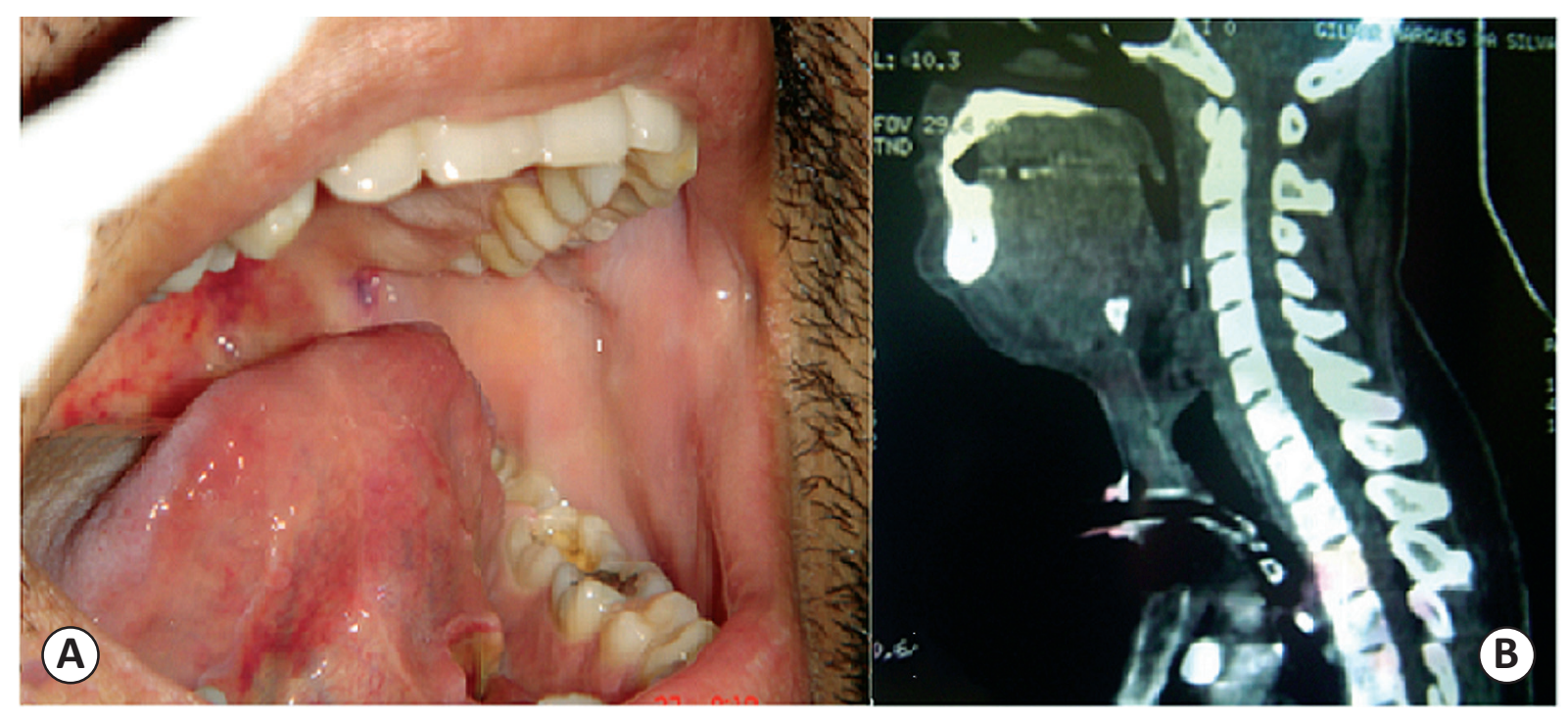

FIGURE 1 A: Tongue protrusion culminating in rapid and progressive airway obstruction. B: Bulging soft tissue in the left hemiface, moving outside the masseter muscle; soft tissue swelling in the anterior cervical region bilaterally, with hypodense areas and impregnation contrast right and inferior to the submandibular gland, noting air density images; reduction of the oropharynx light up the supraglottic region.

\section{DIsCusSION}

Ludwig's angina should be suspected in patients with hard bilateral swelling in the cervical region with concomitant presentations of local pain, sore throat, dysphagia, intense sialorrhea, trismus, high fever, tachycardia, a raised and protruding tongue with voice alteration, stridor, hypoxia, and ventilatory insufficiency. According to Kruger et al., Ludwig's angina is differentiated from other orocervical infections by bilateral impairment and a raised tongue; in the absence of these symptoms, cellulitis may not be considered as Ludwig's angina. Clinical suspicion is essential for early treatment. However, the extent of the disease might be underestimated in $70 \%$ of the cases 5 . In keeping with this notion, hospitalization should be taken as the initial measure, and treatment should be based on 3 important aspects that include upper airway maintenance, drainage or surgical decompression, and intravenous antimicrobial therapy ${ }^{6}$.

In the case of respiratory impairment, the patient should be admitted to the ICU and orotracheal intubation should be postponed. Although the procedure might be blindly 
TABLE 2 - New dengue case definitions from the World Health Organization issued in 2009.

\begin{tabular}{lll}
\hline Dengue without warning signs & \multicolumn{1}{c}{ Dengue with warning signs* } \\
\hline Fever and 2 of the following: & Dengue as defined above with any of the following: & \multicolumn{1}{c}{ Severe dengue } \\
Nausea and vomiting & Abdominal pain or tenderness & Dengue with at least 1 of the following criteria: \\
Rash & Persistent vomiting & Severe plasma leakage leading to: \\
Aches and pains & Clinical fluid accumulation (ascites, pleural effusion) & fluid accumulation with respiratory distress \\
Leucopenia & Mucosal bleeding & Severe bleeding as evaluated by clinician \\
Positive tourniquet test & Lethargy, restlessness & Severe organ involvement \\
& Liver enlargement $>2 \mathrm{~cm}$ & liver: AST or ALT $\geq 1,000$ \\
& Laboratory: increase in HCT concurrent with & CNS: impaired consciousness \\
& rapid decrease in platelet count & failure of heart and other organs
\end{tabular}

*requires strict observation and medical intervention. DSS: dengue shock syndrome; AST: aspartate aminotransferase; ALT: alanine aminotransferase; HCT: hematocrit; CNS: central nervous system.

performed, surgery is life threatening and is therefore not recommended because of local anatomic changes caused by the inflammation. Administration of muscle relaxants might be risky and precipitate occlusion of the airway caused by a loss of pharyngeal muscle tone. Moreover, muscle relaxants could impede intubation and ventilation. Procedures performed while the patient is awake, which enable direct visualization, such as bronchofibroscopy, might be safer and less traumatic ${ }^{7}$. Emergency tracheostomy was performed in this patient as an extreme and exceptional measure that was essential for his survival and performed by a trained surgeon.

Dengue is an acute febrile infectious disease that can be benign or severe. Severe hemorrhagic manifestation is one of the findings that define the severe dengue classification, besides hypovolemic shock and organ dysfunction. These mainly develop once the fever reduces, when plasma extravasation begins (3-7 days), and hemoconcentration, hypoalbuminemia, and cavity effusion are observed. Dengue severity is divided into 3 categories (dengue without warning signs, dengue with warning signs, and severe dengue) according to the new World Health Organization (WHO) classifications (Table 2) ${ }^{4}$.

The appearance of severe thrombocytopenia in an asymptomatic patient 10 days after the onset of dengue, which is the phase when complications should normally remit or normalize, suggests a diagnosis of thrombocytopenic purpura (Table 1). A study conducted by the Federal University of Mato Grosso do Sul, which examined 543 patients, showed that $68.5 \%$ of the patients presented with a platelet count $<150,000 \mathrm{~mm}^{3}$. Moreover, a reduction in platelet count was observed in CD patients from the $3^{\text {rd }}$ day, whereas in dengue hemorrhagic fever (DHF), this was observed from the $1^{\text {st }}$ and $2^{\text {nd }}$ days. The median platelet count in DHF was lower than that in $\mathrm{CD}$. However, the daily evolution was similar, reaching a low level on the $7^{\text {th }}$ day and increasing afterward ${ }^{8}$.

One way of thinking suggests the development of severe thrombocytopenic purpura in response to viral infection in the later phase of the disease. This might explain the initial response to corticosteroids, which increased the platelet count. However, the question remains whether platelet recovery would have occurred regardless of the use of corticosteroids. Randomized, controlled studies are needed to establish the evidence for the possible salutary effects of corticosteroids in increasing the platelet count and improving other symptoms of dengue in addition to defining their optimal dose. Considering this, in addition to the immunological susceptibility caused by dengue, proven association of Ludwig's angina in susceptible individuals, and close temporal correlation, we strongly believe that dengue and corticosteroids aided in the development of Ludwig's angina in the present patient.

This report emphasizes the importance of considering dengue as a predisposing factor for Ludwig's angina and the need for increased suspicion of its diagnosis in patients with a history of dental manipulation, which evolves rapidly with bilateral edema of the soft tissues in the orofacial region.

\section{REFERENCES}

1. Saifeldeen K, Evans R. Ludwig's angina. Emerg Med J 2004; 21:242-243.

2. Ocasio-Tascón ME, Martínez M, Cedeño A, Torres-Palacios A, Alicea E, Rodríguez-Cintrón W. Ludwig's angina: an uncommon cause of chest pain. South Med J 2005; 98:561-563.

3. Ministério da Saúde. Epidemiological Surveillance. National Program for Control of Dengue Fever. Brasília: Ministério da Saúde; 2002.

4. World Health Organization (WHO). Dengue: guidelines for diagnosis, treatment, prevention and control. New edition: WHO; 2009.

5. Kruger G. Oral and Maxillofacial Surgery. $5^{\text {th }}$ ed. Rio de Janeiro: Guanabara koogan; 1984.

6. Montenegro MC, Pereira R, Milani JA. Clinical versus computed tomography evaluation in the diagnosis and management of deep neck infection. Sao Paulo Med J 2004; 122:259-263.

7. Prado R, Salim M. Oral and maxillofacial surgery-Diagnosis and treatment. Rio de Janeiro: Medsi; 2004.

8. Oliveira EC, Pontes ERJC, Cunha RV, Fróes IB, Nascimento D. Hematologic alterations in patients with dengue fever. Braz Soc Trop Med 2009; 42:682-685. 